\title{
O pensamento de Jeannine Verdès-Leroux e o Serviço Social: um resgate crítico
}

\section{The thinking of Jeannine Verdès-Leroux and the Social Work: a critical rescue}

\author{
Ludson Rocha Martins \\ Assistente social das Prefeituras Municipais de Nova Lima (MG) e Pedro Leopoldo (MG), mestre em Serviço \\ Social pela Universidade Federal de Juiz de Fora (UFJF), Belo Horizonte/MG, Brasil. \\ ludsonrocha@gmail.com
}

Resumo: O texto recupera o estudo de Jeannine Verdès-Leroux sobre o trabalho social e o Serviço Social francês. Nesse sentido, trabalha os conceitos centrais da sociologia de Pierre Bourdieu principal influência para o desenvolvimento das ideias da autora. A partir disto, são avaliadas as indicações de Verdès-Leroux acerca do trabalho social e do Serviço Social como dispositivos de controle e violência simbólica.

Palavras-chave: Trabalho social. Serviço Social. Verdès-Leroux. Bourdieu.
Abstract: The paper recovers the study of Jeannine Verdès-Leroux about the French Social Work and Social Service, at the traditional professional context. Approaches the central concepts of sociology of Pierre Bourdieu (but not exhaustively) - main methodological influence on the above author. Thereby are evaluated the Verdès-Leroux indications that address the social service as coherent control system and symbolic violence.

Keywords: Social Work. Social Service. Verdès-Leroux. Bourdieu.

\section{Introdução}

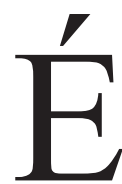

lugar-comum, no debate do Serviço Social brasileiro, a concepção segundo a qual o processo de modernização da categoria, durante a segunda metade do século XX, resultou em um corte profundo, que produziu a deslegitimação dos referenciais teórico-práticos do tradicionalismo profissional, abalados pela hegemonia da corrente denominada por Netto (2011) de Intenção de Ruptura. 
Essa mudança radical consolidou a renúncia às perspectivas que guiaram o passado conservador da profissão, em uma reconfiguração da estrutura teórica do Serviço Social, naquele momento ${ }^{1}$ quase totalmente recomposta. Este trabalho de reelaboração conceitual significou, assim, um recomeço para a pesquisa profissional, com pouca alusão às ideias que antes dominavam as discussões sobre a atuação dos assistentes sociais.

Teve-se, dessa forma, o abandono das narrativas sobre o Serviço Social (de origem europeia e norte-americana) assentadas no funcional positivismo e no confessionalismo religioso, dispensando-se também, embora de modo menos contundente e explícito, a sociologia das profissões como influência para o novo debate que se estabeleceu² (Martins, 2014a e 2014b).

Aqui cabe uma breve digressão para clarear o problema. Sob o ponto de vista conservador, a gênese e a afirmação da ocupação de assistente social seriam uma trama linear dos fatos e sucessos que estruturaram a história profissional, ganhando relevo o papel singular exercido pelas pioneiras do Serviço Social, a adoção de novas teorias na prática e na representação da profissão, bem como a formulação de técnicas e métodos próprios à intervenção dos assistentes sociais.

De acordo com Montaño (2011), o estatuto do Serviço Social era observado a partir de sua especificidade, dada pelo seu objeto "exclusivo" de intervenção. A particularidade da atuação profissional distinguiria a categoria de suas origens - a ajuda e a caridade —, pois a profissão seria a sua forma superior e se legitimaria pela intervenção científica e técnica na personalidade dos indivíduos em situação de pobreza e desvio social.

Esta visão, como há muito se sabe, remonta à própria Mary Richmond (1995), para quem o Serviço Social seria a ocupação que nasce das práticas filantrópicas, ao mesmo tempo que as supera. Para ela, o trabalho profissional deveria se centrar no caso individual, no diagnóstico neutro e preciso das situações sociais problema, que gerariam os atritos entre os sujeitos e a sociedade. O tratamento dessas "patologias" peculiares deveria seguir o modelo clínico: profilaxia dos problemas potenciais ou diagnóstico/terapêutica/cura daqueles que foram identificados, situação em

1. Década de 1980.

2. Dado que esta - em sua versão mertoniana e parsoniana — era uma das antigas e "superadas" bases para a compreensão da trajetória da categoria (Martins, 2014b). 
que o profissional seria o sujeito da ação e, o usuário, o objeto manipulado no decurso da intervenção. Para Richmond (1995), o assistente social deveria recolher diretamente do real as evidências de desajustamento por trás das demandas e do comportamento do usuário (categorizando-as conforme modelos preexistentes) e, a partir disto, aplicar técnicas que levassem à subjetividade do "cliente" (fonte dos problemas) a adequação com o meio.

As bases da atuação profissional estariam, assim, no primado da neutralidade (dado que a categoria não deveria tomar partido nas disputas entre patrões e empregados), no apoliticismo (vista nocividade inerente à política, prejudicial à legitimidade dos assistentes sociais), na verticalidade da relação do profissional com seu público e no praticismo (evidenciado, sobretudo, pela recusa à grande teoria).

O ponto decisivo é que o processo de modernização profissional se concretizou justamente como a luta para superar o esgotamento desse paradigma (a crise profissional), a partir do Movimento de Reconceituação Latino-Americano e da Renovação Brasileira, ${ }^{3}$ que gestaram as condições para a emergência de uma conformação progressista do Serviço Social, responsável por erigir o pensamento marxista como a principal fonte de diálogo da categoria com as ciências sociais.

$\mathrm{O}$ que se consolidou a partir disso foi uma literatura profissional que vai da análise dos fundamentos da profissão (incluindo as reflexões sobre a sua deontolo-

3. Segundo Iamamoto (2009a, p. 22) “o Movimento de Reconceituação do Serviço Social na América Latina teve lugar no período de 1965 a 1975, impulsionado pela intensificação das lutas sociais que se refratavam na universidade, nas ciências sociais, na Igreja, nos movimentos estudantis, dentre outras expressões. Ele expressa um amplo questionamento da profissão (suas finalidades, fundamentos, compromissos éticos e políticos, procedimentos operativos e formação profissional), dotado de várias vertentes e com nítidas particularidades nacionais. Mas sua unidade assentava-se na busca de construção de um Serviço Social latino-americano: na recusa da importação de teorias e métodos alheios à nossa história, na afirmação do compromisso com as lutas dos 'oprimidos' pela 'transformação social' e no propósito de atribuir um caráter científico às atividades profissionais. Denunciava-se a pretensa neutralidade político-ideológica, a restrição dos efeitos de suas atividades aprisionadas em microespaços sociais e a debilidade teórica no universo profissional". Já a "Renovação do Serviço Social Brasileiro foi uma dinâmica diferente que surgiu a partir da obstrução da Reconceituação pelo conservadorismo que emergiu junto com a ditadura em 1964. Assim, a modernização da profissão no país foi um processo alternativo àquele que vinha se desenhando na maioria dos países da América do Sul, outro padrão de resposta à crise profissional — situação posta pela fragilização da categoria frente às necessidades sociais que devia atender. Esta fase histórica foi tanto uma dinâmica que se concretizou por meio de forças progressistas, como conservadoras, que buscavam enfrentar a debilidade profissional no país, conjuntura que fez com que a crítica radical ao Serviço Social entre nós se desenvolvesse de forma tardia" (Martins, 2014a, p. 98; grifos do autor). 
gia, o seu mercado de trabalho, o perfil dos seus agentes), passando pelos estudos sobre os novos movimentos sociais, os problemas relativos às classes e a temática do trabalho, até as investigações sobre o Estado, a gestão pública, as políticas sociais, entre outros assuntos.

Tomando como base as ponderações de Marx sobre a vida moderna, esse caminho se propôs a clarificar a natureza do trabalho do assistente social, dimensionando os elementos materiais e ideopolíticos que o conformam. Os protagonistas dessa discussão já são conhecidos. Trata-se de nomes como Faleiros (2011 e 2007), Iamamoto (2009b) e Netto (2007 e 2011), que forneceram as maiores contribuições para a análise dos fundamentos do Serviço Social, influenciando não só os profissionais brasileiros, mas também boa parte dos profissionais latino-americanos (Martins, 2014a; Montaño, 2011).

Durante esse rearranjo do campo intelectual da categoria, os contributos de tais nomes sofreram notável influência ${ }^{4}$ de uma pesquisadora europeia específica, cuja obra representa, talvez, o maior dos (poucos $\left.{ }^{5}\right)$ exemplos de avaliação direta da profissão pelas ciências sociais contemporâneas, ainda que tal fato não seja notado por grande parte dos analistas.

Jeannine Verdès-Leroux (1986) — comentadora e colaboradora de Pierre Bourdieu -, socióloga e historiadora francesa, nascida em 1941, forneceu aos assistentes sociais uma importante reflexão crítica (de inclinação neoweberiana, mas com grande influência do pensamento radical), sua proximidade das ideias marxistas (Gramsci e o próprio Marx, principalmente) ajudou no amadurecimento da relação do Serviço Social brasileiro com tal corrente. Nessa ótica, aliás, sua maior contribuição reside no rigor e na qualidade da análise que empreendeu, uma amostra da estatura do pensamento social francês, cuja repercussão na América Latina confrontou diversos assistentes sociais, marcados, em relação às assertivas marxianas, pelo ecletismo e pelo mecanicismo vulgar - ao menos até as pesquisas de Iamamoto $^{6}$ (1983).

A investigação de Verdès-Leroux (1986) antecipou temas diversos, posteriormente trabalhados por Netto (2007 e 2011), Iamamoto (2009b) e Faleiros (2007

4. Não temos espaço aqui para demonstrar a extensão dessa influência, porém basta uma leitura minimamente atenta para evidenciar o grande número de menções e citações indiretas de Verdès-Leroux (1986) nas principais obras desses estudiosos.

5. O outro grande exemplo pode ser considerado A polícia das famílias, de Jacques Donzelot (1986).

6. Em parceria com Raul de Carvalho. 
e 2011), situando a gênese do Serviço Social na consolidação do capitalismo europeu no final do século XIX; a conformação da imagem subalterna dos assistentes sociais; o seu perfil feminino; a ligação das pioneiras do Serviço Social com a doutrina social da Igreja; a avaliação do caráter indeterminado da prática profissional; as transformações do discurso da profissão diante das mudanças da conjuntura histórica etc.

Tal contributo constituiu-se, assim, como uma tentativa sistemática de indicar os elementos estruturais que presidem o trabalho do assistente social sob a égide do tradicionalismo, e sua assertividade impressiona e se mantém, em grande medida, o que faz com que seu resgate crítico seja essencial para rastrear e explicitar as fontes teóricas mobilizadas pelos maiores pensadores da categoria na atualidade.

Trazer à tona o conteúdo da obra de Jeannine Verdès-Leroux (1986), ponderando seus limites e possibilidades, é, portanto, fundamental, em vista de sua envergadura e relevância histórica, e, especialmente, pela oportunidade de apresentar um pensamento fecundo e rico, capaz de fornecer subsídios para o aprofundamento do diálogo da profissão com as ciências sociais.

\section{0 pensamento de Jeannine Verdès-Leroux}

Embora seja inegável uma forte e decisiva influência do marxismo nas ideias de Verdès-Leroux (1986, 1987 e 1989), constatada pela linguagem que emprega (que sempre ressalta a importância das classes, da luta de classes e da produção econômica), pelas fontes de que faz uso (por exemplo, Marx, Gramsci, Escola de Frankfurt, entre outros) e pelos objetos que investiga (trabalho social, o campo de poder do Partido Comunista Francês (PCF), o socialismo e os intelectuais cubanos etc.), é como uma representante do debate neoweberiano pautado na sociologia de Pierre Bourdieu (2001, 2003, 2013 e 2014) que a autora se destacou no cenário acadêmico. ${ }^{7}$

Essa inclinação fez com que Verdès-Leroux (1986) centrasse seu olhar nas particularidades daquilo que seria o "campo" do trabalho social, isto é, o conjunto

7. Destarte isso, é importante assinalar que a autora se afasta progressivamente de Bourdieu, sobretudo a partir dos anos 1980 . 
de relações e dispositivos que estabelecem as profissões sociais (e, entre elas, especialmente o Serviço Social) como instituições e práticas laborativas.

A noção de "campo" de Bourdieu (2003) é a fonte que delineia sua perspectiva, permitindo-lhe buscar a especificidade das práticas e identidades dessa área, descrevendo-a como um fenômeno derivado das modernas burocracias públicas e privadas, que se manifestaria em instituições como escolas, hospitais, estabelecimentos psiquiátricos e unidades assistenciais.

Tal posição é comum ao pensamento francês. Nesse contexto, a expressão "trabalho social" se refere a uma ampla área do espaço coletivo, um recorte singular na divisão do trabalho, concernente às especialidades focadas na regulação social. Psicólogos, pedagogos, enfermeiras, visitadores sociais, administradores públicos etc. estariam entre os trabalhadores sociais. O Serviço Social, por sua vez, seria uma das ocupações centrais desse "campo", o grande responsável pela sua identidade.

Inseridas nessa tradição, as ideias de Verdès-Leroux (1986) tentam identificar os elementos de autonomização relativa da intervenção social profissionalizada, isto é, as condições de emergência de um conjunto de estruturas no âmbito da divisão do trabalho, que produzem agentes com posições e disposições particulares, engendrando uma esfera específica de mediação entre as classes sociais, o Estado e o conjunto da sociedade civil. Trata-se, assim, de um sistema conceitual que, partindo de Bourdieu (2001 e 2003), tenta apreender o trabalho social como instrumento de poder e violência (simbólica — voltaremos, posteriormente, a este assunto).

É importante, então, aprofundar as raízes teóricas que informam o debate, clarificando a singularidade do pensamento de Verdès-Leroux (1986) junto à escola francesa. Para tanto, é necessário, antes, voltar a Bourdieu (2001, 2003, 2013 e 2014), indicando os pontos mais decisivos de sua sociologia.

\section{A sociologia de Pierre Bourdieu - Notas introdutórias}

Numa exposição despretensiosa e reduzida, podemos dizer que a teorização de Bourdieu (2001, 2003, 2013 e 2014) — que comporta, inclusive, uma abordagem sintética dos pilares da teoria social moderna (Marx, Weber e Durkheim) — se 
constitui como uma forma peculiar de observar o sistema social e, dentro deste, a relação entre os agentes e as estruturas coletivas.

Tal visão conforma uma tentativa (não importa agora se efetiva ou não) de superar as oposições entre as abordagens micro e macrossocial, entre os enfoques voltados para o estudo do consenso e do conflito, entre a análise dos agentes do mundo social, bem como dos objetos sociais deste mundo.

O seu pressuposto é a existência da vida coletiva como espaço de interações,

um conjunto de posições distintas, exteriores umas às outras, definidas umas em relação às outras por sua exterioridade mútua e por relações de proximidade, de vizinhança ou de distanciamento e também por relações de ordem, como acima, abaixo e entre [...]. (Bourdieu, 2001, p. 19; grifos do autor)

Seria no espaço social que os sujeitos, as instituições e as práticas (individuais ou coletivas) se encontrariam e se processariam, segundo uma ordem de equalização e diferenciação homóloga a certo conjunto de bens e atividades econômicas e simbólicas.

Os indivíduos e os grupos seriam os atores do espaço social. Nas sociedades modernas - sobretudo nas de tipo ocidental —, eles se distribuiriam a partir de dois princípios fundamentais de natureza estruturada e estruturante: o capital econômico - o conjunto de bens, recursos e competências econômicas dominadas pelos agentes ou a eles disponíveis (herança, salários, investimentos etc.) - e o capital cultural (a ordem de elementos, recursos e capacidades na esfera do sentido que se estruturariam segundo a lógica própria do "mercado de bens simbólicos").

Tais forças dariam origem a outros dois tipos de capitais, cada um com seu estatuto singular: o capital social — " "...] o conjunto de recursos reais ou potenciais resultante do fato de um ator pertencer, há muito tempo e de modo mais ou menos institucionalizado, a redes de relações de conhecimento e reconhecimento mútuo" (Milani, 2004, p. 105), e o capital simbólico — dado pelas relações de prestígio e honra, que permitiriam identificar os tipos de agentes do espaço coletivo.

Os ethos dos atores e as suas relações seriam definidos pela sua posição no espaço social. Quanto mais próximos uns dos outros, maiores as chances de se interpelarem e de se identificarem (formando grupos e classes); por conseguinte, maiores as semelhanças entre suas funções, papéis, gostos, crenças e estilos de vida. 
Nessa concepção, também a dominação se estabeleceria com base no espaço social, pois as distâncias entre os grupos e os sujeitos expressariam diferenças de poder, que conformariam relações de força. A sociedade emergiria, assim, como um sistema em processo de integração, se estabeleceria como um constructo hierarquizado, em razão da distribuição desigual do poder e da existência disseminada do privilégio.

O desenvolvimento do corpo coletivo seria uma dinâmica de complexificação crescente, que faria com que a evolução histórica promovesse a diferenciação do mundo em esferas (Bourdieu, 2014) - econômica, política, cultural, jurídica, burocrática etc. - , provocando o surgimento de tipos singulares de relações sociais. Daí que, na analítica de Bourdieu (2001), ganhe proeminência a noção de "campo", usada para representar as múltiplas partes ou frações do espaço social.

Um "campo" seria, dessa forma, um sistema de relações entre posições, disposições e tomadas de posição atribuídos a certos atores e, consequentemente, as estruturas que surgem por intermédio de suas práticas. Seriam microcosmos dotados de alguma autonomia diante do todo social, possuindo, portanto, normas que lhes seriam próprias, ao mesmo tempo que dependeriam do ordenamento da sociedade que os contém.

O seu funcionamento seria tributário dos interesses dos agentes que deles participam, notadamente daqueles que os hegemonizam. A função precípua de um campo seria garantir e legitimar a sua reprodução, tanto interna (para os seus membros), quanto externamente (para a sociedade).

Em suma:

Os campos apresentam-se à apreensão sincrônica como espaços estruturados de posições (ou de postos) cujas propriedades dependem da sua posição nestes espaços e que podem ser analisados independentemente das características dos seus ocupantes (em parte determinadas por elas). Há leis gerais dos campos: campos tão diferentes como o campo da política, da filosofia, o campo da religião tem leis de funcionamento invariantes [...]. Sempre que se estuda um novo campo [...] descobrimos propriedades específicas, próprias de um campo particular, ao mesmo tempo em que fazemos progredir o conhecimento dos mecanismos universais dos campos que se especificaram em função de variáveis secundárias. (Bourdieu, 2003, p. 119)

Todo campo daria origem a um sistema de habitus, responsável por condicionar o comportamento e a psique de seus atores. Estes seriam padrões esquemáticos 
de ação e percepção internalizados pelos indivíduos, a forma pela qual a sociedade reproduz as suas estruturas nos sujeitos, ${ }^{8}$ por meio de "princípios geradores de práticas distintas e distintivas" (Bourdieu, 2001, p. 22).

Os habitus seriam também o meio pelo qual a violência simbólica se realiza, permitindo a criação e a imposição de crenças que levariam os atores a conduzirem suas atividades com base nos critérios hegemônicos. Isto é, haveria em cada agente uma consciência total - a conjunção da consciência individual e da consciência coletiva - que se estruturaria por meio de um processo de transmissão cultural e subjetiva, cuja função seria provocar a inculcação de esquemas de ação e códigos de conduta (sobretudo por meio das relações entre os corpos e, posteriormente, pela linguagem oral e pela imitação).

Por conta dessa aceitação da doxa reinante, a violência simbólica se constituiria como a expressão do conhecimento dos indivíduos acerca dos padrões sociais, que se materializaria no reconhecimento da legitimidade de tais estruturas, o que faria dela um modo de exercer o poder simbólico. O espaço social aparece, então, como o ponto de partida e de chegada da análise, a realidade (última e primeira) responsável pelas possibilidades de ação e representação dos sujeitos.

Daí que para Bourdieu (2013, p. 106):

Todo empreendimento científico de classificação deve considerar que os agentes sociais aparecem como objetivamente caracterizados por duas espécies diferentes de propriedades: de um lado, propriedades materiais que, começando pelo corpo, se deixam denominar e medir como qualquer outro objeto do mundo físico; de outro, propriedades simbólicas adquiridas na relação com sujeitos que os percebem e apreciam, propriedades essas que precisam ser interpretadas segundo sua lógica específica. Isso significa que a realidade social admite duas leituras diferentes: de um lado, aquela armada de um uso objetivista da estatística para estabelecer distribuições (no sentido estatístico e também econômico), expressões quantificadas da repartição de uma quantidade finita de energia social entre um grande número de indivíduos em concorrência, apreendidas por meio de "indicadores objetivos" (ou seja, de propriedades materiais); de outro, a leitura voltada a decifrar significações e a lançar luz sobre as operações cognitivas pelas quais os agentes as produzem e decifram.

8. Esta diferença fundamental é explicada por Bourdieu (2014, p. 143), quando de sua análise da legitimidade do Estado, através da seguinte passagem: "A alternativa indivíduo/estrutura que faz belas dissertações é fraca, pois a estrutura está no indivíduo tanto quanto na objetividade". 
A primeira orientação visa apreender uma "realidade" objetiva inacessível à experiência comum e revelar "leis", isto é, relações significativas, no sentido de não aleatórias, entre as distribuições; a segunda toma como objeto não a "realidade", mas as representações que os agentes dela formam e que fazem toda a "realidade" de um mundo social concebido, à maneira dos filósofos idealistas, como "vontade e representação".

Em síntese, em Bourdieu (2003 e 2013), a vida social seria um emaranhado constituído por campos (ou esferas) relativamente autônomas, cujos atores se relacionariam a partir de parâmetros internalizados, apreensíveis a partir de duas ordens de objetividade (a lógica material e a lógica ideal). Para ele, a prática individual seria uma improvisação determinada por um repertório limitado de opções. As estruturas sociais, por sua vez, tenderiam sempre a perpetuar suas bases, de maneira a repor de forma contínua a disposição corrente dos grupos e sujeitos — daí o porquê de esse pensamento ser, por excelência, uma teorização sobre a reprodução social, e não sobre os processos de mudança e transformação coletiva. ${ }^{9}$

\section{A análise do Serviç̧o Social em Verdès-Leroux}

Dentro desses parâmetros, Jeannine Verdès-Leroux analisou, no final dos anos 1970, a atividade dos assistentes sociais franceses, abordando o contexto tradicional da profissão. Seu intuito foi apreender "o conteúdo e as modalidade da ação [...], as especificidades dos agentes e os princípios diretores" da intervenção do Serviço Social, procurando

uma representação globalmente coerente capaz de fornecer, ao mesmo tempo, as razões de ser da instituição e suas condições de viabilidade, examinando-se, de um lado, a ação que ela produz, as marcas que deixa sobre as frações da classe operária, que são, por assim dizer, o seu alvo, e, de outro lado, o modo de geração das práticas de um grupo definido, que desenvolve suas estratégias profissionais no campo particular construído pelo trabalho social. (Verdès-Leroux, 1986, p. 9)

Tais objetivos são típicos das análises que se orientam a partir de Bourdieu (2001, 2003 e 2013), e, por isso, se referenciam a um método de estudo que

9. O que não significa que Bourdieu (2001, 2003, 2013 e 2014) possa ser taxado de conservador. 
contorna a ênfase no desvendamento das funções das estruturas sociais, focando na busca das particularidades dos fenômenos humanos. Dessa forma, para Verdès-Leroux (1986) não basta definir a profissão por aquilo que faz; é preciso, ainda, esclarecer a legalidade singular que estabelece o seu modo de atuação. Ou seja, a análise deve desvelar não apenas o estado das posições, mas também as disposições e as tomadas de posição dos agentes.

Nessa angulação, a autora afirma que o Serviço Social seria uma área amorfa e pouco consolidada. Tratar-se-ia de um setor do mercado de bens simbólicos em íntima relação com o mercado de bens econômicos. Sua atividade potencializaria e encobriria a ordem das relações materiais, dado que sua atribuição primordial seria fortalecer o controle sobre os sujeitos que desempenham papéis subordinados no cenário coletivo, notadamente as classes trabalhadoras, promovendo nelas a inculcação dos valores e princípios dominantes.

Como lembra Verdès-Leroux (1986, p. 9),

este campo deve sua especificidade à ausência quase completa de uma demanda social solvável, em troca dos serviços que ele oferece. O dinamismo desse campo, enaltecido pelo meio, deve-se à natureza das tarefas que lhes são atribuídas e ao mandato que the é conferido - os quais não podem ser inteiramente definidos, nem codificados, e deixam, assim, aos profissionais, uma parte de autonomia e de iniciativa na produção do que deles se espera. Tal dinamismo é produto de agentes concretos, e sua origem não se encontra na intervenção explicitamente organizadora da instância de direção (os poderes públicos), mas sim, espontaneamente, nas vastas possibilidades de reconversão que a própria imprecisão dos objetivos e o arbítrio dos métodos e a ausência de sanções oferecem a algumas frações de classe. No plano material, elas encontram um mercado de trabalho pouco estruturado, em que ocupar uma posição equivale amplamente a criá-la, e, no plano simbólico, um setor de recuperação, onde podem aplicar-se disposições e um capital cultural que não encontram curso no interior do setor dominante.

Aqui aparece a mais importante das antecipações de Verdès-Leroux (1986), referente ao caráter indiferenciado da prática profissional, problema que, anos mais tarde, seria analisado por Iamamoto (2009b) e Faleiros (2007 e 2011), recebendo sua melhor resolução por meio das pesquisas de Netto (2007).

Quanto a tal aspecto, diz este autor que o Serviço Social seria uma tecnologia que atua sobre as refrações da questão social no horizonte da vida cotidiana e, por 
isto, não poderia ter delimitada a especificidade de sua prática. A fluidez e a heterogeneidade desta estariam assentadas na multiplicidade de sequelas da questão social, na indefinição que marca a instrumentação técnica do Serviço Social, bem como nas próprias determinações da vida cotidiana, pouco afeita a suspensões e à homogeneização. Daí que Netto (2007) veja o trabalho dos assistentes sociais como polifacético e polimórfico, um modo de intervenção caracterizado pela "inespecificidade operatória".

Embora acentue tais elementos, Verdès-Leroux (1986) focaliza as particularidades da profissão, derivadas não de sua atuação imediata, mas da elaboração de um ethos que marca seus agentes, cujo papel central seria a promoção da doxa dominante, difundida por meio de uma ação sistemática de transubstanciação ideológica na regulação das relações cotidianas entre a burguesia e as classes trabalhadoras.

Para a autora, o Serviço Social nasceu ligado, num primeiro momento, à assistência organizada - um conjunto de estruturas e práticas impulsionadas por intensos conflitos sociais colocados pela industrialização e pela urbanização, e que se posicionou como um contramovimento à politização da classe operária a partir do ideário socialista.

Com o seu amadurecimento, a profissão se estatuiu, num segundo momento, como um dispositivo coerente de controle. Sua ação teria como suporte a intervenção na família, na infância, na feminilidade e na velhice (a porta de entrada para o relacionamento com os trabalhadores, principalmente os operários).

A condição feminina seria, sobretudo, uma peculiar determinação do Serviço Social. Não apenas a ação das assistentes sociais se poria como um processo de difusão dos padrões de gênero e das sexualidades dominantes, como o gênero e a sexualidade seriam, eles próprios, um meio privilegiado de disciplinamento das famílias operárias e dos "inaptos sociais". A ação do Serviço Social se apresentaria, portanto, como um mecanismo de subalternização feminina, um dispositivo de promoção dos comportamentos de gênero socialmente aceitos. Por isso a ênfase no papel da mulher e do lar, o apreço pela moralidade, a necessidade de promover entre as "moças" o uso adequado da vestimenta, os modos corretos de sentar, levantar e caminhar, de anunciar a importância da família, do celibato, do cuidado com os filhos, da higiene etc.

Como alerta Verdès-Leroux (1986), a relação do Serviço Social com as questões de gênero e sexualidade possui diversas implicações. Não se trata somente de, por 
meio do trabalho social, afirmar a doxa hegemônica, mas de inferiorizar e denegrir o quadro de referência dos grupos subalternos. Uma das resultantes dessa dinâmica foi a reprodução do lugar subordinado das próprias assistentes sociais como mulheres e profissionais, mesmo daquelas que faziam parte dos grupos superiores. ${ }^{10}$

Daí que,

Reprimidas, vigiadas, castigadas, criadas no receio do pecado, na exaltação do sofrimento e do sacrifício, na condenação dos prazeres, as jovens [assistentes sociais] [...] nada mais podem e sabem fazer, senão reprimir, vigiar etc. Elas falam das "gaiatices" das operárias e qualificam seu cansaço como "nervosismo de criança". A infantilização é também marcante pela ameaça muito frequente de sanções: censurar, repreender, admoestar, "chicotear" (tal expressão, é claro que em sentido figurado, diz bem, no entanto, da vontade de "castigar" - e da segurança que elas têm do seu direito de fazê-lo). (Verdès-Leroux, 1986, p. 25-26)

Nessa perspectiva, a autora destaca, por exemplo, que o desnível que marcou o contato entre a clientela feminina e a categoria profissional no início do século XX tranquilizava e protegia as assistentes sociais, e só podia, ao contrário,

impressionar as mulheres do povo e domesticá-las. Ele atenua, amortece, policia o encontro, despindo-o dos seus aspectos mais chocantes e brutais. Por fim, a assistente improvisada, senhora de seu tempo, de suas atividades, rica e benemerente, pode dar a impressão de ser "íntima", como isto lhe é aconselhado: visto que, segura de reencontrar, logo que o queira, sua vida mundana - e, melhor ainda, de aí ocupar, de agora em diante, um lugar singular —, ela se sente confortada pela imensidão da distância que a separa das mulheres do povo. (Verdès-Leroux, 1986, p. 17)

As assistentes sociais seriam, nesses termos, um corpo funcional especializado na distensão dos conflitos sociais, contribuindo para impedir o questionamento da ordem existente em suas múltiplas dimensões (materiais e ideais). O habitus de tais profissionais teria se forjado através dos parâmetros ideoculturais das protoformas do Serviço Social (a ajuda e a caridade), os seus valores exprimiriam, por isso,

10. A este respeito muito bem esclareceu Bourdieu (2001) acerca da existência de frações dominadas nas classes dominantes, bem como de frações dominantes das classes dominadas. 
os condutos do caritativismo, do vínculo religioso, a negação da política e, no início, o desprestígio da teorização.

Em seus primórdios, a profissão privilegiava o "ser em detrimento do pensar" (Verdès-Leroux, 1986, p. 10), todavia, conferia um grande valor às instâncias de formação, que selecionavam seus agentes segundo seu enquadramento no projeto profissional (conduta ilibada, experiência em atividades assistenciais, o desejo e a disposição de "servir", a capacidade de falar em público, de trabalhar com grupos etc.).

A fragilidade do Serviço Social, oriunda da forma acessória, e não fundamental, de suas atividades, teria o potencial para colocá-lo numa situação difícil diante de outras ocupações mais consolidadas, o que fez com que a profissão se protegesse por meio de um forte corporativismo (demonstrado, por exemplo, pela constante celebração da categoria efetivada pelos seus quadros).

Segundo Verdès-Leroux (1986), o terreno de recrutamento dos agentes profissionais, durante a segunda metade do século XX, era a pequena burguesia (sobretudo o laicato católico), ao contrário de seu início, em que prevaleciam profissionais oriundas das classes abastadas (as senhoras da sociedade).

A necessidade de sistematização e justificação ideológica do trabalho levou as assistentes sociais a desenvolver modos de ação pautados no discurso científico (de fato, uma abordagem pseudocientífica), cuja resultante era a psicologização das relações sociais, concretizada a partir de estratégias interventivas, como o casework.

Quanto a esse ponto, a discussão de Verdès-Leroux (1986) ganha relevo especial. Segundo a autora a abordagem de casos, entendida como ajuda psicossocial individualizada, situava os afetos dos sujeitos como o centro da intervenção social, a moralidade individual, cujas mazelas se esconderiam por trás das carências materiais, deveria ser o grande alvo da ação. O objetivo, então, seria elaborar junto ao "cliente" um trabalho pormenorizado. Cada encontro, cada conversa, encaminhamento ou pactuação seria uma oportunidade para a sensibilização, que procuraria atacar as fraquezas subjetivas do indivíduo e de sua família, segundo um diagnóstico estruturado.

A inovação desse método, em relação às convencionais diagnoses realizadas pelo Serviço Social, consistiu no recurso à psicanálise - observada como a melhor fonte de inspiração para a condução e os registros do diálogo entre profissional e usuário. No plano ideal, o casework foi, na verdade, uma estratégia construída para 
reforçar a imagem da profissão, uma tentativa de ampliar, por meio de suportes técnicos, a visibilidade e a legitimidade dos assistentes sociais.

No entanto, a nova proposta pouco ou nada alterou a arbitrariedade do trabalho social, permanecendo sua consecução forçosa e chauvinista, agora encoberta por um discurso pretensamente racional.

Em outras palavras:

Baseado numa versão espiritualizada da "ciência psicanalítica", o casework fornece à assistente social a autoridade necessária para impor sua intervenção ao "cliente", que não protesta, nem contra a ausência de resposta concreta ao seu pedido (formalmente legítimo), nem contra as manipulações que esse pedido acarreta, ou seja, o poder de esconder seu caráter objetivo de violência, tal como esta se revela nas entrelinhas dos comentários em que o solicitante é expressamente relegado à humilhante posição de um incapaz [...]. (Verdès-Leroux, 1986, p. 69)

Esse caráter impositivo do trabalho profissional levou Verdès-Leroux (1986) a considerar que o traço marcante do Serviço Social seria a violência simbólica. A prática dos assistentes sociais, voltada claramente para a normalização daqueles que sofrem sua intervenção, moldar-se-ia como um processo sofisticado de repressão cultural e ideológica, os bens simbólicos que rearranja se juntariam aos bens e processos econômicos, fortalecendo os esquemas de dominação existentes.

Essa determinação elucidaria, inclusive, as inconsistências da legitimidade profissional - tida por Verdès-Leroux (1986) como pouco consolidada e até mesmo pouco consolidável.

Noutros termos mais precisos:

Exercida por uma fração dominada, mas objetivamente integrada no plano cultural e moral, à classe dominante, cujo arbítrio cultural e moral ela reproduz - e dispondo, nos limites de seu mandato, de uma autoridade delegada sobre as camadas dominadas -, a ação do trabalho social [e dentro deste, do Serviço Social] conduz ao questionamento da legitimidade da sua intervenção: questionamento que, se for encarado do ponto de vista da população visada, conduz, por sua vez, ao questionamento da violência simbólica necessária a sua imposição. [...] Essa noção de violência simbólica impõe-se, tanto mais, quanto as modalidades de intervenção provocam, localmente, reações violentas de rejeição contra um projeto de inculcação e de controle, 
que ainda não conseguiu fazer esquecer completamente o arbítrio de sua imposição. De fato, a extensão do trabalho social [e do Serviço Social] é relativamente recente; a submissão de seus agentes à classe cujos interesses materiais e morais eles expressam nem sempre foi dissimulada; as incompatibilidades ligadas às diferenças de origem entre os trabalhadores sociais e sua "clientela" nem sempre foram suficientemente mediadas; em resumo [...] o trabalho social [e, por conseguinte, o Serviço Social] ainda não se eximiu totalmente da necessidade de produzir a sua própria justificação. (Verdès-Leroux, 1986, p. 10)

As vulnerabilidades da legitimidade profissional decorreriam, assim, da instabilidade intrínseca do "campo" em que o Serviço Social está inscrito. Nele a profissão se depararia com as resistências do público demandatário, além das insuficiências de suas respostas para as necessidades desse público.

Como mostra Verdès-Leroux (1986), a evolução do Serviço Social francês caminhou junto com a situação sociopolítica do país. Os saltos organizativos das classes trabalhadoras (o público-alvo do Serviço Social) e a forma como o Estado e as classes dominantes reagiram a eles impactaram diretamente a profissão, que precisou adaptar o seu discurso e o seu modus operandi para se legitimar frente às alterações do contexto histórico.

Assim, é o acirramento dos embates entre as classes que explica por que o Serviço Social francês muda, ao longo do século XX, a sua linguagem e os seus parâmetros de ação, desenvolvendo práticas e "gramáticas" cada vez mais dissimuladas a partir da incorporação de influências do pensamento das ciências sociais e da multiplicação dos aparatos interventivos que cultivavam uma imagem técnica e asséptica para a profissão.

Daí que para cada grande transformação no cenário coletivo exista uma grande mudança na conjuntura profissional. Verdès-Leroux (1986) menciona, sobre esse ponto, a existência de alterações profundas no contexto da profissão. Quanto mais se estende o século XX, mais se complexifica o quadro profissional. Progressivamente, as senhoras da sociedade são substituídas por pequenas burguesas (o novo grupo central de recrutamento de assistentes sociais); a força do discurso religioso se esvanece em prol de fontes acadêmicas; onde existia consenso passa a haver conflito; onde havia apenas homogeneidade passa a existir heterogeneidade.

Enfim, para Verdès-Leroux (1986), o trabalho social e o Serviço Social francês adentraram os anos 1970 em profunda crise. No entanto ela não representou a 
derrocada da profissão, posta, por exemplo, por uma redução de sua demanda. Tratou-se, na verdade, de uma crise de legitimidade, da inviabilização do discurso e das práticas tradicionais do Serviço Social, condenadas, naquele momento, pelo seu próprio arcaísmo. O dinamismo da conjuntura social francesa não mais poderia ser enfrentado pelos antigos discursos e ações dos assistentes sociais. Assim, seja por um viés conservador, seja pela opção por um caminho progressista, a profissão passou a enfrentar o desafio de sua modernização.

\section{Considerações finais}

Um balanço crítico da pesquisa de Jeannine Verdès-Leroux (1986) acerca do trabalho social e do Serviço Social só pode revelar a existência de um conjunto de ideias rico e profundo, capaz de exibir determinações fundamentais da profissão em seu contexto tradicional. Isto, entretanto, não significa a ausência de falhas e limites em sua análise. Uma avaliação, mesmo que breve, é capaz de indicar que a autora não tratou de um dos elementos mais essenciais ao desenvolvimento da profissão: a política social. Por conta disto, em sua visão, o trabalho social e o Serviço Social permanecem ligados à assistência organizada, mesmo adentrando com força cada vez maior nas agências e organismos estatais.

Também o tratamento dos temas da economia política não é suficientemente realizado, ainda que a autora valorize e ressalte, a todo momento, as implicações dos problemas e questões da produção. A maior ressalva a ser realizada, porém, se refere não a esses pontos, mas à utilização do conceito de campo. Na sociologia de Bourdieu (2001, 2003, 2013 e 2014), esse dispositivo conceitual é empregado para esclarecer as particularidades das esferas do espaço social. O problema é que o seu emprego no âmbito do trabalho social produz um paradoxo, que consiste em procurar as especificidades de uma área qualificada de amorfa, cujos suportes interventivos não seriam codificados ou codificáveis.

Essa contradição, inclusive, força Verdès-Leroux (1986) a delimitar os traços singulares da profissão, não a partir de suas práticas e discursos, mas de sua imagem e função social, definidas como uma forma de controle social e violência simbólica.

Apesar dessas restrições (em verdade pequenas, quando abordamos a totalidade das ideias dessa estudiosa), há que se destacar os grandes méritos de sua 
análise. O pensamento de Verdès-Leroux (1986) expõe a cultura profissional do Serviço Social francês até os anos 1970, o caráter arbitrário da prática profissional tradicional, bem como sua determinação enquanto atividade que denegria e inferiorizava os grupos sociais subalternos. Sua argumentação merece destaque, principalmente, no que se refere à abordagem do casework e à análise da relação entre o Serviço Social e as questões de gênero e sexualidade, as quais ${ }^{11}$ ainda não foram superadas pela literatura brasileira.

Revisitar esse pensamento é, portanto, uma tarefa de grande valia, seja para melhor apreender o conteúdo das fontes e influências que balizaram os maiores nomes do Serviço Social no país, seja para aprofundar o conhecimento sobre os próprios fundamentos dessa prática profissional em seu passado conservador.

\section{Recebido em 21/2/2016 - Aprovado em 1/6/2016}

\section{Referências bibliográficas}

BOURDIEU, P. Razões práticas: sobre a teoria da ação. 3. ed. São Paulo: Papirus, 2001.

Algumas propriedades dos campos. In: Questões de sociologia. Lisboa: Sociedade Unipessoal, 2003. p. 119-126.

Curso de $1^{\circ}$ de fevereiro de 1990. In: . Sobre o Estado: cursos no Collège de France (1989-1992). São Paulo: Companhia das Letras, 2014. p. 80-104.

. Capital simbólico e classes sociais. Novos Estudos Cebrap, São Paulo, n. 96, p. 105-115, jul. 2013. Disponível em: <http://www.scielo.br/scielo.php?script=sci_arttext\&pid= S0101-33002013000200008\&lng=pt\&nrm=iso $>$. Acesso em: 31 jan. 2016.

DONZELOT, J. A polícia das famílias. Rio de Janeiro: Graal, 1986.

FALEIROS, V. de P. Estratégias em Serviço Social. 10. ed. São Paulo: Cortez, 2011. . Saber profissional e poder institucional. 7. ed. São Paulo: Cortez, 2007. 159 p.

11. Em nossa opinião. 
IAMAMOTO, M. V. O Serviço Social na contemporaneidade. 18. ed. São Paulo: Cortez, 2009a.

. O Serviço Social na cena contemporânea. In: CFESS/ABEPSS (Orgs.). Serviço Social: direitos sociais e competências profissionais. Brasília: CFESS/Abepss, 2009b.

; CARVALHO, R. de. Relações sociais e Serviço Social no Brasil: esboço de uma interpretação histórico-metodológica. 2. ed. São Paulo: Cortez, 1983. 380 p.

MARTINS, L. R. Crítica da legitimidade na teoria das profissões e suas contribuições para o debate sobre os fundamentos do Serviço Social. Dissertação (Mestrado) - Universidade Federal de Juiz de Fora, Juiz de Fora, 2014a.

Teoria das profissões e a análise dos fundamentos do Serviço Social. Verinotio, revista on-line de Filosofia e Ciências Humanas, n. 20, p. 64-81, out. 2014b. Disponível em: $<\mathrm{http}$ //verinotio.org/Verinotio_revistas/n20/5_Martins.pdf >. Acesso em: 10 fev. 2016.

MILANI, C. Teorias do capital social e desenvolvimento local: lições a partir da experiência de Pintadas (Bahia, Brasil). Organizações e Sociedade, Salvador, número especial, v. 11. p. 95-113, 2004. Disponível em: <http://www.portalseer.ufba.br/index.php/revistaoes/article/ view/12637/8905>. Acesso em: 14 fev. 2016.

MONTAÑO, C. A natureza do Serviço Social: um ensaio sobre sua gênese, a "especificidade" e sua reprodução. 2. ed. São Paulo: Cortez, 2011.

NETTO, J. P. Capitalismo monopolista e Serviço Social. 6. ed. São Paulo: Cortez, 2007. . Ditadura e Serviço Social: uma análise do Serviço Social no Brasil pós-64. 15. ed. São Paulo: Cortez, 2011.

RICHMOND, M. El caso social individual. Madri: Talasa, 1995.

VERDÈS-LEROUX. J. Trabalhador social: prática, habitus, ethos, formas de intervenção. São Paulo: Cortez, 1986.

Le parti communiste, les intellectuels et la culture (1956-1985). Paris: Éditions Fayard, 1987.

. Le rêve des intellectuels et le Régime Cubain (1959-1971). Paris: Gallimard/ L'Arpenteur, 1989. 